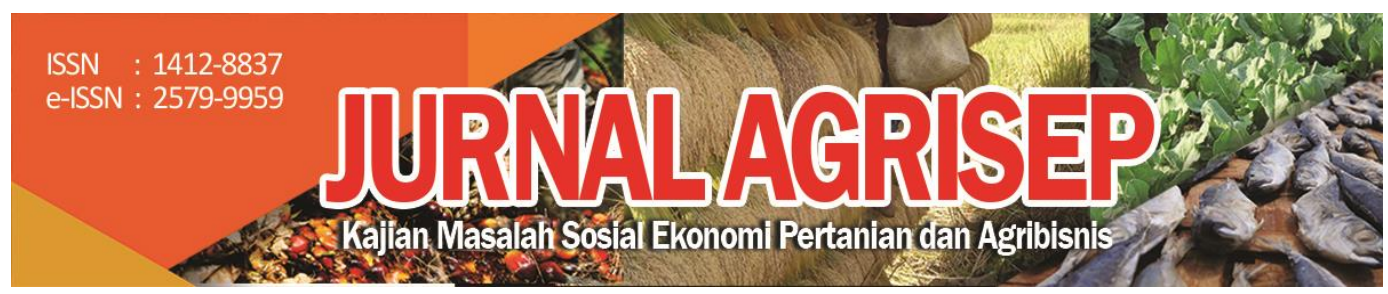

DOI: 10.31186/jagrisep.19.2.229-240

\title{
PERAN PENYULUH PERTANIAN DALAM BUDIDAYA PADI SALIBU DI KABUPATEN TANAH DATAR PROVINSI SUMATERA BARAT
}

\author{
The Role Of Agricultural Extentions In Salibu Technology In Tanah \\ Datar District, West Sumatera Province \\ Heri Bachrizal Tanjung ${ }^{\left.{ }^{凶}\right)}$, Sri Wahyuni ${ }^{2)}$, Ifdal ${ }^{3)}$ \\ 1),2),3) Jurusan Sosial Ekonomi Fakultas Pertanian Universitas Andalas \\ Email: hbtanjung25@yahoo.com
}

\begin{abstract}
Agricultural extension acts as agents of change directly related to farmers. Likewise, the role of agricultural extension in Tanah Datar District is in the salibu extension program, so this study aims to describe the role of agricultural extension in salibu cultivation in Tanah Datar District. The research was conducted from August to October 2018 in Tanah Datar District, West Sumatera. This type of research was descriptive research that was designed qualitatively, where the method used was focus group discussion (FGD). The data source was selected purposively (intentionally) consisting of 17 agricultural extension workers in Tanah Datar District, which consisted of district extension agents, coordinator extension, and agricultural extension agents. The results showed that the role of agricultural extension in the salibu cultivation in Tanah Datar was as a motivator for farmers in conducting salibu cultivation. Extensions became counselors and agents of rice transfer technology so that farmers became aware, willing, capable, and skilled in conducting millet rice cultivation. Extensions convey the advantages of salibu, carry out demonstration plots, conduct guidance and provide training activities through field schools, as well as mentoring maintenance untill harvest.
\end{abstract}

Keywords: agents, extention, role, salibu

\section{ABSTRAK}

Penyuluh pertanian berperan sebagai perubahan yang langsung berhubungan dengan petani. Demikian juga dengan peran penyuluh pertanian di Kabupaten Tanah 
Datar dalam program penyuluhan padi salibu, sehingga penelitian ini bertujuan untuk melihat dan mendeskripsikan peran penyuluh pertanian dalam budidaya padi salibu di Kabupaten Tanah Datar. Penelitian dilaksanakan pada bulan Agustus hingga Oktober 2018 di Kabupaten Tanah Datar, Provinsi Sumatera Barat. Jenis penelitian ini adalah penelitian deskriptif yang didesain secara kualitatif, di mana metode yang digunakan adalah metode focus group discussion (FGD). Sumber data dipilih secara purposive (sengaja) yang terdiri atas 17 orang penyuluh pertanian di Kabupaten Tanah Datar, yang terdiri atas penyuluh kabupaten, penyuluh koordinator, dan penyuluh pertanian. Hasil penelitian menunjukkan bahwa peran penyuluh pertanian dalam budidaya padi salibu di Kabupaten Tanah Datar adalah sebagai motivator petani dalam melakukan budidaya padi salibu. Penyuluh menjadi pembimbing dan agen transfer teknologi padi salibu agar petani menjadi tahu, mau, mampu, serta terampil dalam melakukan budidaya padi salibu. Penyuluh menyampaikan keunggulan-keunggulan padi salibu, melaksanakan demplot, melakukan bimbingan dan memberikan kegiatan pelatihan melalui sekolah lapang, serta pendampingan pemeliharaan padi salibu hingga panen.

Kata Kunci: penyuluh, penyuluhan, peran, salibu

\section{PENDAHULUAN}

Penyuluhan pertanian memiliki peran penting dalam mendorong pembangunan pertanian serta meningkatkan produksi pangan di suatu negara. Hal tersebut menjadi salah satu alasan utama semakin berkembangnya minat dan ketertarikan berbagai stakeholders dalam beberapa dekade terakhir terhadap penyuluhan pertanian (Van den Ban dan Hawkins, 1999). Penyuluhan pertanian sebagai salah satu bentuk pendidikan informal diharapkan dapat meningkatkan partisipasi petani dalam mengembangkan usahatani yang berujung pada peningkatan keberdayaan petani. Setiana (2005) menjelaskan bahwa penyuluhan berperan di antaranya sebagai alat dalam diseminasi informasi, proses perubahan perilaku, pendidikan, penerangan, dan proses rekayasa sosial. Lebih lanjut, Sadono (2008) menyatakan penyuluhan mampu membawa keberhasilan, memajukan sektor pertanian, memenuhi kebutuhan pangan, hingga meningkatkan pendapatan petani dan keluarganya.

Penyuluh merupakan pelaku penting dalam kegiatan penyuluhan pertanian. Dalam menjalankan tugas dan kewajibannya, penyuluh dibutuhkan untuk distribusi dan diseminasi pesan dan informasi berbentuk teknologi dan inovasi pertanian dengan diksi yang dapat dengan mudah dipahami oleh para pelaku utama yang terdiri atas petani dan keluarganya, sehingga mampu menyuguhkan kejelasan dan penerangan mengenai berbagai pengetahuan baru, sehingga pada akhirnya dapat mengubah sikap dan meningkatkan keterampilan tentang hal-hal yang belum diketahui. Selain itu, penyuluh juga harus mampu mendorong petani berswadaya dalam upaya peningkatan produksi dan perubahan perilaku para pelaku utama yang menjadi sasaran penyuluhan, terutama peningkatan kesejahteraan mereka.

230 | Heri Bachrizal Tanjung, Sri Wahyuni, Ifda; Peran Penyuluh Pertanian... 
Sebagai negara agraris, sebagian besar penduduk Indonesia merupakan individu dengan pencaharian utama sebagai petani Salah satu komoditas pangan yang selalu mengalami peningkatan permintaan adalah beras. Data yang diperoleh dari statistik Balitbangtan (2015) memperlihatkan penurunan laju pertumbuhan produksi padi, sebaliknya biaya produksi per satuan luas mengalami peningkatan selama lima tahun belakangan. Agar dapat mengatasi persoalan tersebut, pemerintah mencanangkan produksi padi nasional harus mengalami 1,5\% kenaikan per tahun. Oleh sebab itu, berbagai upaya dengan menciptakan berbagai terobosan dan teknologi baru untuk meningkatkan produksi dan produktivitas padi terus dilakukan oleh pemerintah (Balitbangtan, 2015; Dirjen Tanaman Pangan Kementan, 2017).

Peningkatan produksi padi terus diupayakan oleh pemerintah dengan berbagai program seperti Gerakan Penerapan Pengelolaan Tanaman Terpadu (GP-PTT) dan berbagai Upaya Khusus (Upsus) (Balitbangtan, 2015; Dirjen Tanaman Pangan Kementan, 2017). Melalui berbagai temuan klinis dari peneliti serta hasil indiginous knowledge (kearifan lokal) masyarakat, terdapat beragam jenis budidaya tanaman padi di Indonesia. Beragam pola budidaya dari kebiasaan dan adat istiadat masyarakat setempat terbukti memiliki berbagai keuntungan, seperti pola tanam tumpang sari di Jawa Timur (Setiawan, 2009), Kejrun Blang dan Kanuri Blang di Aceh (Ansor dan Nurbaiti, 2014; Maifianti et al. 2014; Putra et al. 2012), hingga budidaya padi salibu (salin ibu) di Sumatera Barat (Erdiman, 2013).

Teknologi budidaya padi salibu, selanjutnya disebut teknologi salibu, merupakan salah satu bentuk inovasi yang berasal dari kearifan lokal masyarakat yang berkembang di Sumatera Barat. Dalam beberapa sumber, teknologi salibu juga dikenal sebagai padi ratun. Teknologi salibu adalah teknologi budidaya padi yang memanfaatkan batang bawah setelah panen sebagai penghasil tunas/anakan yang akan dipelihara (Erdiman, 2013). Erdiman (2013) juga menyebutkan bahwa beberapa keuntungan teknologi salibu antara lain adalah hemat dari segi biaya, benih, tenaga kerja, air, dan ramah lingkungan. Teknologi salibu juga meningkatkan indek panen dari dua kali menjadi tiga hingga empat kali panen dalam satu tahun, serta dapat meningkatkan produktivitas padi per unit area dan per unit waktu. Selain itu, produktivitas bisa sama bahkan lebih tinggi dari tanaman utamanya sehingga meningkatkan produksi setiap musim tanam (Erdiman et al, 2013).

Hingga saat ini, teknologi salibu merupakan inovasi telah disebarluaskan dengan gencar oleh penyuluh kepada petani, terutama di Kabupaten Tanah Datar sebagai daerah yang pertama kali mengembangkannya. Penyebarluasan tersebut tidak terlepas dari peran aktif penyuluh yang secara intensif terus mendorong petani untuk menerapkan teknik budidaya tersebut tersebut. Melalui hasil penelitian sebelumnya oleh Wahyuni et al. (2017), diketahui bahwa penerapan teknologi salibu jika dilihat dari berbagai, salah satunya 
adalah dukungan penyuluh dalam memberikan informasi budidaya padi salibu kepada petani. Menurut Bulkis (2015), informasi yang diterima petani disebabkan oleh adanya interaksi, sehingga diperlukan penyaluran informasi usahatani padi salibu melalui saluran yang sudah melembaga di petani, di mana hal tersebut memungkinkan untuk dilakukan dengan bantuan penyuluh.

Sebagai agen perubahan, penyuluh merupakan individu yang langsung berhubungan dengan para pelaku utama, yaitu petani dan keluarganya. Berdasarkan UU No. 16 Tahun 2006, fungsi penyuluhan di antaranya meliputi kegiatan pembelajaran, peningkatan kemampuan petani, membantu menganalisis dan memecahkan masalah, serta memberikan kemudahan akses petani terhadap teknologi dan informasi agar dapat mengembangkan usahanya. Hal yang sama juga berlaku bagi penyuluh pertanian di Kabupaten Tanah Datar dalam program penyuluhan padi salibu, sehingga penting untuk melihat bagaimana peran penyuluh pertanian dalam program budidaya padi salibu. Akan tetapi, riset mengenai padi salibu sebagian besar diarahkan pada aspek teknis dan budidaya, seperti halnya riset oleh Suwandi et al. (2012), Susilawati dan Purwoko (2012), Erdiman et al. (2013), Erdiman (2013), Sinaga et al. (2015, dan Herlinda et al. (2015). Kajian mengenai peran penyuluh pertanian dalam mendukung budidaya padi salibu masih belum banyak dilakukan. Padahal, peran penyuluh sangat krusial dan merupakan faktor kunci keberhasilan program padi salibu sebab menurut Jarmie (2000), penyuluh berperan sebagai motivator, edukator, dinamisator, organisator, komunikator, hingga penasihat petani, termasuk petani salibu. Oleh karena itu, dengan menyadari besarnya peran penyuluh dalam program budidaya padi salibu di Kabupaten Tanah Datar, penelitian ini bertujuan untuk mendeskripsikan peran penyuluh pertanian dalam budidaya padi salibu di Kabupaten Tanah Datar.

\section{METODE PENELITIAN}

Riset ini dilakukan dari bulan Agustus hingga Oktober 2018 di Kabupaten Tanah Datar, Sumatera Barat, di mana lokasi penelitian ditentukan secara sengaja (purposive) disebabkan karena Kabupaten Tanah Datar merupakan salah satu daerah sentra produksi padi dan telah mengembangkan Teknologi Padi Salibu di Provinsi Sumatera Barat. Jenis penelitian ini adalah penelitian deskriptif yang didesain secara kualitatif untuk mendapatkan gambaran dan informasi yang lebih mendalam untuk melihat peran penyuluh pertanian dalam penyuluhan budidaya padi salibu di Kabupaten Tanah Datar. Metode yang digunakan dalam penelitian ini adalah metode focus group discussion (FGD) yang bertujuan untuk mengeksplorasi masalah yang spesifik berkaitan dengan peran penyuluh pertanian dalam budidaya padi salibu di Kabupaten Tanah Datar (Kresno et al., 1999). Sumber data penelitian ini berjumlah 17 penyuluh pertanian Kabupaten Tanah Datar yang dipilih secara purposive (sengaja). Sumber data tersebut terdiri atas penyuluh kabupaten,

232 | Heri Bachrizal Tanjung, Sri Wahyuni, Ifda; Peran Penyuluh Pertanian... 
penyuluh koordinator, dan penyuluh pertanian. Data penelitian ini terdiri atas data primer dan data sekunder, yang dikumpulkan dengan melakukan wawancara langsung secara mendalam, observasi, dan studi dokumentasi.

\section{HASIL DAN PEMBAHASAN}

\section{Karakteristik Penyuluh Pertanian}

Karakteristik individu penyuluh merupakan indentitas kepribadian yang melekat pada di setiap individu penyuluh sejak lahir, serta dipengaruhi juga oleh lingkungan tempat ia tumbuh dan berkembang. Karakteristik individu penyuluh yang dilihat dalam penelitian ini terdiri atas umum, tingkat pendidikan formal, pendidikan non formal, lama menjadi penyuluh, jabatan dan jenis kelamin, seperti yang disajikan pada Tabel 1.

Tabel 1 memperlihatkan bahwa umumnya penyuluh pertanian yang melakukan penyuluhan budidaya padi salibu di Kabupaten Tanah Datar adalah penyuluh perempuan berusia dewasa (30-49 tahun), serta umumnya lama masa kerja penyuluh tersebut masih terbilang baru (8-17 tahun). Hal ini menunjukkan bahwa sebagian besar penyuluh merupakan penyuluh yang masih sangat produktif. Penyuluh umumnya juga merupakan individuindividu yang memiliki pendidikan formal tinggi (SMA-Perguruan Tinggi), sehingga penyuluh memiliki wawasan yang lebih baik, pemikiran yang lebih sistematis, dan keterbukaan serta pemahaman terhadap inovasi yang lebih cepat dan lebih baik. Menurut Peranginangin et al. (2016), penyuluh berpendidikan tinggi menjadi modal penting untuk mengembangkan kegiatan penyuluhan pertanian yang berkualitas, sehingga tenaga penyuluh pertanian memiliki keunggulan baik di bidang spiritual, keagamaan, pengendalian diri, kepribadian, kecerdasan, akhlak mulia serta ketrampilan yang dapat mendorong penyuluh untuk bekerja dan melakukan perannya dengan lebih baik.

Selain pendidikan formal, tenaga penyuluh juga didukung dengan pendidikan nonformal yang terdiri dapat berupa bimbingan teknis (bimtek), pelatihan, dan sebagainya yang berfungsi untuk meningkatkan kompetensi penyuluh pertanian. Tabel 1 memperlihatkan bahwa umumnya penyuluh pertanian telah mengikuti 1-2 kali pendidikan nonformal terkait padi salibu dalam rentang dua tahun terakhir (2017-2018). Berdasarkan wawancara bersama penyuluh di lapangan, hal tersebut karena pelatihan dan bimbingan teknis mengenai padi salibu dilaksanakan tidak terlalu sering dan hanya menyangkut hal-hal teknis dan utama seperti budidaya dan irigasi. Hal tersebut sejalah dengan temuan Hanafiah et al. (2013) yang menyatakan bahwa keterbatasan kegiatan pelatihan yang diterima oleh penyuluh disebabkan oleh terbatasnya pelatihan yang diberikan oleh pemerintah daerah dan pusat. 
Tabel 1. Karakteristik Penyuluh Pertanian di Kabupaten Tanah Datar

\begin{tabular}{|c|c|c|c|}
\hline No. & Karakteristik Individu & Frekuensi orang) & Persentase $(\%)$ \\
\hline \multirow[t]{4}{*}{1.} & Umur & & \\
\hline & Muda ( $<30$ tahun) & 0 & 0,0 \\
\hline & Dewasa (30-49 tahun) & 9 & 52,9 \\
\hline & Tua ( $\geq 50$ tahun) & 8 & 47,1 \\
\hline \multirow[t]{4}{*}{2.} & Tingkat Pendidikan Formal & & \\
\hline & Rendah (SD) & 0 & 0,0 \\
\hline & Sedang (SMP) & 0 & 0,0 \\
\hline & Tinggi (SMA-Perguruan Tinggi) & 17 & 100,0 \\
\hline \multirow[t]{4}{*}{3.} & Pendidikan Non Formal & & \\
\hline & Rendah (tidakpernah) & 2 & 11,8 \\
\hline & Sedang (1-2 kali) & 9 & 52,9 \\
\hline & Tinggi (3-4 kali) & 6 & 35,3 \\
\hline \multirow[t]{4}{*}{4.} & Lama Menjadi Penyuluh & & \\
\hline & Baru (8-17 tahun) & 7 & 41,2 \\
\hline & Sedang (18-27 tahun) & 4 & 23,5 \\
\hline & Tinggi (28-38 tahun) & 6 & 35,3 \\
\hline \multirow[t]{4}{*}{5.} & Jabatan & & \\
\hline & Penyuluh Pertanian & 12 & 70,6 \\
\hline & Koordinator BPP & 3 & 17,6 \\
\hline & Penyuluh Kabupaten & 2 & 11,8 \\
\hline \multirow[t]{4}{*}{6.} & JenisKelamin & & \\
\hline & Perempuan & 13 & 76,5 \\
\hline & Laki-laki & 4 & 23,5 \\
\hline & Jumlah & 17 & 100,0 \\
\hline
\end{tabular}

Sumber: Data Primer, 2018

\section{Kedudukan Padi Salibu sebagai Program Unggulan}

Sebagai salah satu bentuk kearifan lokal masyarakt di Sumatera Barat, teknologi salibu yang juga dikenal sebagai padi ratun memiliki berbagai keunggulan dan potensi yang sangat baik dalam mendukung peningkatan produktivitas padi nasional. Oleh sebab itu, pada tahun 2013 BPTP Solok kembali mengencarkan penelitian teknologi salibu sebagai salah satu upaya untuk mewujudkan tujuan pemerintah untuk swasembada beras 2015-2019 (RKT Kementan, 2015). Selain itu, permintaan beras nasional yang terus mengalami peningkatan, alih fungsi lahan pertanian menjadi sektor non prtanian, hingga terbatasnya variertas unggul terutama di dataran tinggi serta terbatasnya teknologi budidaya padi juga menjadi alasan pengembangan teknologi salibu (Erdiman et al., 2013). Erdiman et al. (2013) menjelaskan lebih lanjut bahwa teknologi salibu merupakan aktivitas budidaya padi ratun

234 | Heri Bachrizal Tanjung, Sri Wahyuni, Ifda; Peran Penyuluh Pertanian... 
dengan memanfaatkan batang bawah setelah panen untuk menghasilkan tunas atau anakan baru yang berfungsi sebagai pengganti bibir pada sistem tanam pindah (ta-pin), sehingga dapat kembali dipelihara sebagai padi baru.

Potensi teknologi salibu yang sangat besar karena memiliki berbagai keutamaan dibandingkan dengan teknologi budidaya padi lainnya menjadi akar pendorong semakin gencarnya penelitian teknologi salibu. Berbagai keuntungan yang disebutkan oleh Erdiman et al. (2013) mengenai teknologi salibu antara lain adalah bahwa teknologi ini lebih hemat dibandingkan dengan teknologi budidaya padi lainnya, baik dari biaya, waktu, benih, tenaga kerja, air dan irigasi, serta ramah lingkungan. Teknologi salibu juga dapat meningkatkan produktivitas padi per unit area dan per unit waktu, dan meningkatkan indek panen (IP) dari sekali menjadi dua sampai tiga kali panen setahun. Jika dibandingkan dengan teknologi ratun konvensional, teknologi salibu mampu menghasilkan jumlah anakan yang lebih banyak dan seragam, dengan produktivitas yang sama bahkan lebih tinggi dari tanaman utamanya sehingga mampu meningkatkan produksi setiap musim tanam.

Penerapan budidaya padi salibu dengan memanfaatkan varietas berdaya hasil tinggi, tentu akan lebih menggairahkan aktivitas usahatani, karena dapat diperoleh tambahan hasil yang sangat nyata (Erdiman et al, 2013). Teknologi salibu telah diperkenalkan sebagai salah satu program unggulan Kementerian Pertanian yang berbasis kearifan lokal. Teknologi salibu telah diadopsi pada lahan seluas 10.000 hektar di seluruh Indonesia (Direktorat Jenderal Tanaman Pangan Kementerian Pertanian, 2017), antara lain telah diujicobakan di Pulau Jawa, Kalimantan, Sulawesi, Nusa Tenggara Barat, dan sebagainya (Balitbangtan, 2015).

Sumatera Barat juga telah menerapkan teknologi salibu pada beberapa daerah, seperti Kabupaten Dharmasraya, Kabupaten Agam, Kabupaten Solok, Kota Padang Panjang, dan Kabupaten Tanah Datar. Sebagai daerah asal mula berkembangnya padi salibu, Kabupaten Tanah Datar telah menjadikan padi salibu sebagai program pertanian unggulan. Hasil wawancara bersama responden dan hasil FGD bersama para penyuluh pertanian tentang padi salibu di Kabupaten Tanah Datar menunjukkan bahwa program padi salibu dijadikan program unggulan karena keberhasilan uji coba di demplot pertanian, diikuti dengan keuntungan-keuntungannya. Keuntungan yang didapat dari padi salibu menurut penyuluh adalah meningkatkan hasil produksi, hemat biaya produksi, hemat benih, hemat air, hemat tenaga kerja, dan ramah lingkungan.

Hasil penelitian menunjukkan bahwa terdapat beberapa dukungan pemerintah daerah Kabupaten Tanah Datar terhadap padi salibu sebagai program unggulan daerah di bidang pertanian. Menurut hasil wawancara dengan responden, dukungan tersebut adalah disediakannya dana dari APBD untuk bantuan saprodi seperti benih dan pupuk, penyediaan alsintan berupa 
mesin potong untuk kelompok tani, serta menyelenggarakan sekolah lapang dengan sistem demcara dan demplot. Pemerintah juga menyediakan media untuk kebutuhan kegiatan penyuluhan yang terdiri atas media cetak seperti pamflet dan media elektronik. Sementara itu, pemerintah juga memberikan fasilitas kepada penyuluh yang melakukan penyuluhan padi salibu berupa kendaraan roda dua untuk menjangkau lokasi kegiatan dan biaya bahan bakar minyak. Pemerintah juga memberikan kelengkapan admininstrasi serta ATK untuk kebutuhan kegiatan penyuluhan padi salibu. Namun, penyuluh menilai bahwa bantuan sarana dan prasarana yang diberikan oleh pemerintah masih kurang memadai, baik untuk penyuluh sendiri maupun untuk petani melalui kelompok tani. Penyuluh menyatakan bahwa belum seluruh kelompok tani mendapatkan bantuan alsintan berupa mesin potong. Selain itu, bantuan BBM yang diberikan kepada penyuluh belum mencukupi terutama jika hendak mencapai wilayah kerja yang jauh dan dilakukan kontiniu setiap hari.

\section{Peran Penyuluh Pertanian dalam Budidaya Padi Salibu}

Esensi penyuluhan pertanian di Indonesia bukan hanya sebagai pelancar pembangunan, akan tetapi jauh melebihi hal tersebut. Sebagaimana yang disebutkan oleh Mardikanto (2009), penyuluhan pertanian telah berperan sebagai pemicu dan pemacu pertumbuhan dan pembangunan pertanian jauh sejak sebelum kemerdekaan. Hubeis (2007) mengartikan penyuluhan sebagai proses pembelajaran (pendidikan nonformal) yang ditujukan untuk para pelaku utama penyuluhan, yaitu petani dan keluarganya, yang mana berperan besar dalam pencapaian tujuan pembangunan pertanian. Peran penyuluh pertanian meliputi peran penyuluh sebagai pembimbing petani, organisator dan dinamisator petani, teknisi, serta penghubung antara lembaga penelitian dengan petani. Inten et al. (2017) menyebutkan dalam aktivitas pendampingan terhadap pelaku utama program penyuluhan (petani dan keluarganya), penyuluh berperan dalam mendampingi dan memfasilitasi petani agar dapat meningkatkan produktivitas sehingga mampu meningkatkan kesejahteraan dan kualitas hidup petani dan keluarganya.

Penyuluh pertanian memiliki peran penting dalam kesuksesan pelaksanaan program padi salibu di Kabupaten Tanah Datar. Berlian (2014) menyebutkan bahwa aktivitas penyuluhan dapat mendorong peningkatan kemampuan petani dalam mengembangkan usahataninya agar dapat menjadi lebih produktif, efisien, dan menguntungkan, dalam rangka meningkatkan kesejahteraan hidup. Sejalan dengan hal tersebut, maka peran penyuluh sangat penting dalam kegiatan budidaya padi salibu agar petani dapat mengelola usahatani padi salibu dengan maksimal.

Penelitian ini menunjukkan bahwa peran penyuluh pertanian adalah sebagai motivator petani dalam melakukan budidaya padi salibu. Penyuluh menjadi pembimbing dan agen transfer teknologi padi salibu agar petani 
menjadi tahu, mau, mampu, serta terampil dalam melakukan budidaya padi salibu. Penyuluhan yang diberikan oleh penyuluh menyangkut semua aspek budidaya. Dalam kegiatan penyuluhannya, penyuluh menyampaikan keunggulan-keunggulan padi salibu, melaksanakan demplot, melakukan bimbingan dan memberikan kegiatan pelatihan melalui sekolah lapang, serta pendampingan pemeliharaan padi salibu hingga panen. Hal tersebut sesuai dengan tugas pokok dan fungsi penyuluh yang diamanatkan di dalam UU No. 16 Tahun 2006 di antaranya fungsi pembelajaran, peningkatan kemampuan petani, membantu menganalisis dan memecahkan masalah, serta memberikan kemudahan akses kepada petani terhadap teknologi dan informasi.

Namun, masih terdapat beberapa kendala dalam penyuluhan budidaya padi salibu. Hasil penelitian menunjukkan bahwa kendala tersebut terbagi atas kendala teknis dan kendala sosial budaya. Kendala teknis yang dihadapi dalam penyuluhan budidaya padi salibu adalah tidak/belum semua nagari melaksanakan padi salibu karena keterbatasan sarana terutama irigasi; topografi daerah yang tidak sesuai dengan budidaya salibu; kondisi petani/ikan/lahan yang kurang memadai; petani terlambat melakukan penyiangan karena masih banyak petani yang mengeluh mengenai sulitnya melakukan penyiangan yang lebih banyak dari biasanya; varietas, umur panen, dan panen salibu yang dilakukan lebih awal sehingga petani masih keberatan atau sulit mengubah kebiasaan budidaya yang lama; satu hamparan dari lahan petani tidak seluruhnya masuk sebagai lahan kelompok; dan kendala dalam melakukan teknis budidaya salibu secara keseluruhan. Selain itu, saat ini (tahun 2018), kendala teknis yang sangat mengganggu petani adalah serangan dari hama tikus yang menyebabkan gagal panen pada beberapa lahan petani.

Sementara itu, kendala sosial budaya dalam melaksanakan budidaya padi salibu disebutkan oleh penyuluh adalah masih sulitnya mengubah perilaku dan sikap petani agar tertib dalam melakukan budidaya padi salibu; sistem kepemilikan lahan yang masih menggunakan sistem sewa, bagi hasil, atau tanah ulayat, sehingga petani tidak dapat mengolah usahatani sesuai dengan keinginan mereka; dan budaya istirahat setelah panen, padahal budidaya salibu mengharuskan petani untuk langsung turun kembali ke sawah untuk melakukan pengolahan selanjutnya setelah panen.

Selain kendala yang disebutkan di atas, kendala yang juga dihadapi oleh penyuluh adalah kekurangan sumberdaya atau tenaga penyuluh terampil di lapangan. Banyaknya daerah binaan penyuluh yang melebihi kapasitas menyebabkan kinerja penyuluh menjadi tidak optimal. Terkait hal tersebut, Setiawan (2005) menjelaskan bahwa kendala pelaksanaan penyuluhan adalah kurangnya sumberdaya penyuluhan, baik dari segi kualitas maupun kuantitas. Selain itu, kurangnya sarana dan prarana yang didapatkan oleh penyuluh juga menjadi kendala penyuluh dalam melakukan kegiatan penyuluhan di wilayah kerjanya. Seperti halnya temuan Allen et al. (2015) yang menyebutkan bahwa 
kendala yang dihadapi penyuluh adalah luasnya area kerja penyuluh menyebabkan kinerja penyuluh menjadi terhambat karena keterbasan bantuan sarana dan prasarana berupa kendaraan dinas yang diberikan, kurangnya bantuan yang diberikan untuk penyuluh seperti kendaraan dinas dan BBM menyebabkan penyuluh pertanian di Kabupaten Tanah Datar juga kesulitan mengakses semua wilayah kerja untuk budidaya padi salibu. Oleh karena itu, penting agar penyuluh dicukupkan bantuan sarana dan prasarananya agar dapat bekerja secara optimal dalam melakukan kegiatan penyuluhan padi salibu di Kabupaten Tanah Datar.

\section{SIMPULAN DAN SARAN}

\section{Simpulan}

Hasil penelitian ini menunjukkan bahwa dalam budidaya padi salibu di Kabupaten Tanah Datar, penyuluh pertanian berperan sebagai motivator petani dalam melakukan budidaya padi salibu. Penyuluh menjadi pembimbing dan agen transfer teknologi padi salibu agar petani menjadi tahu, mau, mampu, serta terampil dalam melakukan budidaya padi salibu. Penyuluh menyampaikan keunggulan-keunggulan padi salibu, melaksanakan demplot, melakukan bimbingan dan memberikan kegiatan pelatihan melalui sekolah lapang, serta pendampingan pemeliharaan padi salibu hingga panen.

\section{Saran}

Berdasarkan kekurangan yang didapatkan dari hasil penelitian, peneliti menyarankan untuk meningkatkan sumberdaya penyuluh, baik dari sisi kuantitas karen masih kurangnya tenaga penyuluh, maupun dari sisi kualitas dengan memberikan pelatihan, bimtek, dan sebagainya yang dapat mendukung kemampuan penyuluh padi salibu. Selain itu, penting untuk mencukupkan dukungan sarana dan prasarana bagi penyuluh baik dari sisi transportasi, BBM, tunjangan, dan sebagainya agar penyuluh dapat melaksanakan tugasnya dengan maksimal.

\section{DAFTAR PUSTAKA}

Allen HF, Batubara MM, Iswarini H. 2015. Kendala Penyuluh dalam Melaksanakan Aktivitas Penyuluhan pada Usahatani Kopi di Kecamatan Dempo Utara Kota Pagar Alam. SOCIETA. 4(2): 105 - 110. Ansor M, Nurbaiti. 2014. Relasi Gender Dalam Ritual Kenduri Blang pada Masyarakat Petani di Gampong Sukarejo Langsa. At-Tafkir 7(1): 48-66. [Balitbangtan] Balai Penelitian dan Pengembangan Pertanian. 2015. Panduan Teknologi Budidaya Padi Salibu. Jakarta: Kementerian Pertanian. 
Berlian M. 2014. Peran Penyuluh Pertanian Lapangan dan Partisipasi Petani dalam Program FEATI serta Pengaruhnya terhadap Pendapatan Petani di Kecamatan Banyuasin III Kabupaten Banyuasin. Jurnal Matematika, SainS, dan Teknologi. 15 (1): 52-62.

Bulkis B. 2015. Analisis Jaringan Komunikasi Petani Tanaman Sayuran (Kasus Petani Sayuran di Desa Egon, Kecamatan Waigette, Kabupaten Sikka, Provinsi Nusa Tenggara Timur). Jurnal Matematika, Sains, dan Teknologi, 16(2): 28-42.

[Dirjen Tanaman Pangan] Direktorat Jenderal Tanaman Pangan. 2017. Pedoman Pelaksanaan Kegiatan Padi 2017. Jakarta: Kementerian Pertanian.

Erdiman. 2013. Teknologi Salibu Meningkatkan Produktivitas Lahan (3-6 Ton/Ha/Tahun) dan Pendapatan Petani (Rp.15-25 Juta/Tahun). Balai Pengkajian Teknologi Pertanian Sumatera Barat.

Nieldanina, Misran. 2013. Inovasi Teknologi Salibu Meningkatkan Produktivitas Lahan, Mendukung Swasembada Pangan Berkelanjutan. Balai Pengkajian Teknologi Pertanian Sumatera Barat.

Hanafiah MA, Rasyid W, Purwoko A. 2013. Hubungan Karakteristik, Motivasi dan Kompetensi terhadap Produktivitas Kerja Penyuluh Pertanian di Kota Bengkulu. AGRISEP. 13 (1): 69 - 84.

Herlinda S, Dewi R, Adam T, Suwandi, Wijaya A. 2015. Struktur komunitas laba-laba di ekosistem padi ratun: pengaruh aplikasi Beauveria bassiana (Balsamo). Jurnal Entomologi Indonesia. 12(2): 91-99.

Hubeis AV. 2007. Motivasi, Kepuasan Kerja dan Produktivitas Penyuluh Pertanian Lapangan: Kasus Kabupaten Sukabumi. Jurnal Penyuluhan. 3 (2) : 90-99.

Inten SM, Elviana D, Nover BRS. 2017. Peranan Penyuluh Pertanian dalam Peningkatan Pendapatan Petani Komoditas Padi di Kecamatan Tanjungselor Kabupaten Bulungan Kalimantan Utara. Agrifor. 16(1): 103-108.

Inten SM, Elviana D, Nover BRS. 2017. Peranan Penyuluh Pertanian dalam Peningkatan Pendapatan Petani Komoditas Padi di Kecamatan Tanjungselor Kabupaten Bulungan Kalimantan Utara. Agrifor. 16(1): 103-108.

Jarmie MJ. 2000. Peranan Ilmu Penyuluhan Pembangunan Menuju Pembangunan Pertanian yang Berwawasan Agribisnis dalam Pemberdayaan Sumberdaya Manusia Menuju Terwujudnya Masyarakat Madani. Prosiding Seminar (ed. Pambudi, H.R. dan A.K. Adhi). Bogor: Pustaka Wirausaha Muda.

Kresno S, Ella Nurlaela H, Endah Wuryaningsih, IwanAriawan. 1999. Aplikasi Penelitian Kualitatif dalam Pencegahan dan Pemberantasan Penyakit Menular, Fakultas Kesehatan Masyarakat Universitas Indonesia 
bekerja sama dengan Direktorat Jenderal Pemberantasan Penyakit Menular dan Penyehatan Lingkungan Pemukiman Depkes RI. Jakarta. Maifianti KS, Sarwoprasodjo S, Susanto D. 2014. Komunikasi Ritual Kanuri Blang sebagai Bentuk Kebersamaan Masyarakat Tani Kecamatan Samatiga Kabupaten Aceh Barat Propinsi Aceh. Jurnal Komunikasi Pembangunan. 12(2): 30-35.

Peranginangin MI, Silalahi FRL, Siregar R. 2016. Hubungan Karakteristik Penyuluh Dengan Kinerja Penyuluh Pertaniandi Kabupaten Simalungun. Agrica Ekstensia. 10(2): 35-44.

Putra AWS, Hariadi SS, Harsoyo. 2012. Pengaruh Peran Penyuluh dan Kearifan Lokal terhadap Adopsi Inovasi Padi Sawah di Kecamatan Montasik Kabupaten Aceh Besar. KANAL. 1(1): 85-101.

Ritonga ES. 2015. Uji Adaptasi Galur - Galur Padi Ratun Di Lahan Pasang Surut Kabupaten Pelalawan Provinsi Riau. Prosiding Seminar Nasional Lahan Suboptimal.

[RKT Kementan] Rencana Kerja Tahunan Kementrian Pertanian. 2014. Rencana Kerja Tahunan Kementrian Pertanian Tahun 2015. Jakarta: Kementerian Pertanian.

Sadono D. 2008. Pemberdayaan petani: paradigma baru penyuluhan pertanian di Indonesia. Jurnal Penyuluhan. 4(1): 65-74.

Setiana, L. 2005. Pengertian Dasar Penyuluhan Pertanian. Jakarta (ID): Gramedia.

Setiawan E. 2009. Kearifan Lokal Pola Tanam Tumpangsari di Jawa Timur. Agrovigor 2(2): 79-89.

Setiawan IG. 2005. Masalah-masalah penyuluhan pertanian. Jurnal Penyuluhan. 1(1):57-61.

Sinaga PH, Trikoesoemaningtyas, Sopandie D, Aswidinnoor H. 2015. Daya Hasil dan Stabilitas Ratun Galur Padi pada Lahan Pasang Surut. Penelitian Pertanian Tanaman Pangan. 34(2): 97-104.

Susilawati, Purwoko BS. 2012. Pengujian Varietas dan Dosis Pupuk untuk Meningkatkan Pertumbuhan dan Hasil Ratun-Padi di Sawah Pasang Surut.Jurnal Pengkajian dan Pengembangan Teknologi Pertanian. 15(1): 47-54.

Suwandi, Ammar M, Irsan C. 2012. Aplikasi Ekstrak Kompos Meningkatkan Hasil dan Menekan Penyakit Padi Sistem Ratun di Sawah Pasang Surut Kabupaten Banyuasin. Jurnal Lahan Suboptimal. 1(2): 116-122.

Undang-Undang Republik Indonesia No. 16 Tahun 2006. 2006. Sistem Penyuluhan Pertanian, Perikanan, dan Kehutanan. Jakarta. BadanPengembangan SDM Pertanian Departemen Pertanian.

Van den Ban, AW., dan Hawkins, H.S. 1999. Penyuluhan Pertanian. Yogyakarta (IDE): Kanisius. 